oligoarthritis was detected in $25 \%$ of patients, RF-negative polyarthritis-in $22.5 \%$, extended oligoarthritis-in 10\%, RF-positive polyarthritis-in 10\%, systemic-onset JIA-in 12.5\%, enthesitis-related JIA-in 15\%, undifferentiated arthritis-in 2,5\%, psoriatic arthritis-in $2,5 \%$ of patients. BMD ( $<<0.000001)$ in the lumbar spine (LS) were lower in female with JIA than in healthy people. Femoral neck (FN) BMD $(p<0.000001)$, total body (TB) BMD $(p<0.000001)$ were lower in patients with JIA than in healthy people. The BMD was significantly lower at the LS $(p<0.001)$ and at the TB $(p<0.01)$ in both groups, and at the FN $(p<0.001)$ in patients aged $20-29$ years in comparison with healthy group. Z-score $<-2$ SD in young females was detected in $40 \%$ of patients in the LS, in $25 \%$ of patients in the $\mathrm{FN}$, in $35 \%$ of patients in the TB and $52.5 \%$ of patients in ultradistal forearm, and T-score $<-2.5$-in $2.5 \%$ in LS, 2.5\%-FN, 37.5\%-TB, 22.5\%-ultradistal forearm. Osteopenia by T-score at the LS was found in $42.5 \%$, of the FN-42.5\%, TB-37.6\%, ultradistal forearm-22.5\% of patients.

Conclusions: The presence of JIA in childhood had negative effects on the formation of peak bone mass and BMD at young female.

Disclosure of Interest: None declared

DOI: 10.1136/annrheumdis-2018-eular.6255

\section{AB1357 RISK FACTORS FOR CYTOMEGALOVIRUS REACTIVATION IN PATIENTS WITH CONNECTIVE- TISSUE DISEASE; SINGLE-CENTREPROSPECTIVE COHORT STUDY}

Y. Ota, Y. Kaneko, T. Takeuchi. Division of Rheumatology, Department of Internal Medicine, KEIO UNIVERSITY SCHOOL OF MEDICINE, Tokyo, Japan

Background: Cytomegalovirus (CMV) reactivation is one of serious opportunistic infections for immunosuppressed patients, therefore, identifying patients at risk for CMV reactivation is of importance. However, no prospective study about CMV reactivation in connective tissue disease (CTD) has been reported.

Objectives: To identify risk factors relevant with $\mathrm{CMV}$ reactivation in patients with CTD during remission-induction therapy.

Methods: Consecutive CTD cases who started immunosuppressive therapy from February until December 2017 were enrolled. Serum CMV-IgG was measured before the induction therapy, and subsequently, CMV pp65 antigen was monitored weekly. Patients were divided into 2 groups according to the presence or absence of CMV reactivation, and risk factors for $\mathrm{CMV}$ reactivation were analysed.

Results: Sixty six cases were enrolled. Mean age was $59.9 \pm 17.9$ y/o, and female was $68.2 \%$. The underlying diseases were following; anti-neutrophil cytoplasmic antibody-associated vasculitis 18, systemic erythematosus 11, polymyositis/dermatomyositis 9, IgG4-related disease 7, giant cell arteritis 6 , and others 15 . The initial dose of glucocorticoid (GC) was $50.8 \pm 11.5 \mathrm{mg} /$ day $(0.92 \pm 0.15 \mathrm{mg} / \mathrm{kg} / \mathrm{day})$ as prednisolone (PSL) with additional methylprednisolone (mPSL) pulse therapy being conducted in 17 (25.8\%). Concomitant immunosuppressive therapies were intravenous cyclophosphamide (IVCY) in 25, mycophenolate mofetil 9, and calcineurin inhibitor 7 , tocilizumab 2 , infliximab 1 , abatacept 1 , and rituximab 1 . None of $10 \mathrm{CMV}-\mathrm{lgG}$ negative patients developed CMV reactivation. Among $56 \mathrm{CMV}$ IgG positive patients, CMV reactivated in 20 patients (35.7\%). Among those, CMV infection occurred in 2 patients (hematopoietic injury and hepatitis). Previous history of $G C$ administration ( $p=0.032)$, initial $G C$ dose $(p=0.033)$, mPSL pulse therapy $(p=0.018)$, IVCY $(p=0.003)$, and low lymphocyte count 1 week after treatment initiation $(p=0.023)$ were significantly related with $C M V$ reactivation.

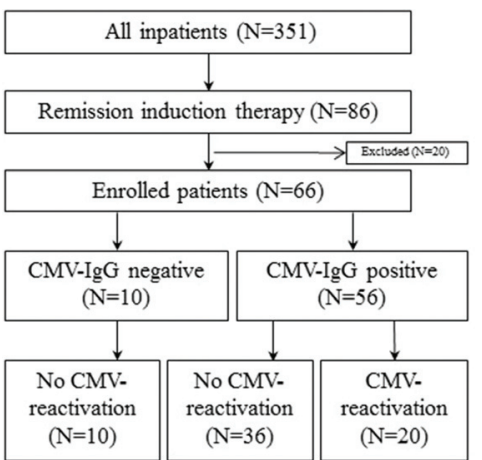

Abstract AB1357 - Figure 1. Patient flow of this study.
Conclusions: While no CMV reactivation occurred in CMV-IgG negative cases, treatment regimen and low lymphocyte count were associated with CMV reactivation in CMV-IgG positive CTD cases.

Disclosure of Interest: None declared

DOI: 10.1136/annrheumdis-2018-eular.4391

\section{Validation of outcome measures and biomarkers}

\section{\begin{tabular}{|l|l}
\hline AB1358 INFECTIOUS ANTIBODIES REPERTOIRE IN &
\end{tabular} RHEUMATOID ARTHRITIS}

A. Schmiedl ${ }^{1}$, S. Reuter ${ }^{1}$, A. Lerner ${ }^{1}$, S. Brunner ${ }^{1}$, A. Schwarting ${ }^{2}$, T. Matthias ${ }^{3}$. ${ }^{1}$ RandD, Aesku.KIPP Institute, Wendelsheim; ${ }^{2}$ Department of Internal Medicine, Johannes Gutenberg-University, Mainz; ${ }^{3} \mathrm{CEO}$, Aesku.KIPP Institute, Wendelsheim, Germany

Background: The incidence of infectious diseases in the RA ADAPTHERA study by ELISA antibody screening and the differences in infectious distribution in active or low active disease patients was explored.

Methods: Sera from 88 naive RA patients out of the ADAPTHERA study cohort, disease duration $<6$ months, were tested for antibody titers against: Herpes simplex virus 1 and 2 ( $\mathrm{HSV} 1+2, \lg G$ and $\lg M$ ) Helicobacter pylori (HP, $\lg A$ and $\lg G$ ) Cytomegalovirus (CMV, lgG and lgM), Toxoplasma gondii (Toxo, IgG), Adenovirus (lgG and $\lg M)$, Epstein Barr virus (EBV, $\lg G$ and $\lg M)$, and Parvovirus $B 19$ (P$B 19, \lg G$ ) were determined by using NovaLisa from NovaTec Immundiagnostica GmbH, GERMANY. Borrelia (IgG and IgM) titers were determined by AESKULISA and confirmed by Western blot (AESKUBLOTS) by AESKU.DIAGNOSTICS GmbH and Co. KG, GERMANY.

Results: $82 \%$ RA patients were found to be positive for HSV1 +2 IgG ( $2 \% \lg M$ positive), $8 \%$ for Adenovirus ( $\operatorname{lgA}$ ), $77 \%(\operatorname{lgG})$, and $1 \%(\lg M)$. $99 \%$ for $\mathrm{EBV}-\lg G$ (no $\operatorname{lgM}$ positive). $53 \%$ ( $\operatorname{lgG}$ ), and $26 \%$ (IgM) for CMV. $38 \%$ for $\mathrm{HP}-\lg G$ and $15 \%$ for $\lg A$ and $79 \%$ for P-B19- $\lg G(3 \% \lg M) .6 \%$ for Borrelia-IgM and $14 \%$ for $\lg G$. A slightly increase was found for EBV sera positivity $(99 \% \lg G)$, compared to the normal population.

Conclusions: Limited evidence exists regarding the impact of the disease activity on the susceptibility for infections, possibly due to the close association of RA disease activity and therapy dependent dosage of immunosuppressive treatment. Still, some infections may present memory contact, presenting an epiphenomenon. On the contrary, they might play an active role in RA pathophysiology.

Disclosure of Interest: None declared

DOI: 10.1136/annrheumdis-2018-eular.6272

\section{$\mathrm{AB} 1359$ \\ TRANSLATION, CULTURAL ADAPTATION AND VALIDATION OF THE ITALIAN VERSION OF THE BILD: THE BILDIT}

A. Santoni ${ }^{1}$, C. Tani ${ }^{1}$, V. Lorenzoni ${ }^{2}$, C. Stagnaro ${ }^{1}$, E. Elefante ${ }^{1}$, R. Vagelli ${ }^{1}$, L. Carli ${ }^{1}$, G. Turchetti ${ }^{2}$, M. Mosca ${ }^{1} .{ }^{1}$ University of Pisa; ${ }^{2}$ Institute of Management, Scuola Superiore Sant'Anna, Pisa, Italy

Background: Evaluation of organ damage is one of the most important assessments in SLE patients; the SLICC/DI is a physician -driven instrument widely used to assess organ damage in SLE. Patient-reported outcomes (PROs), selfassessments that are not being interpreted by a clinician, are gaining a central role as outcome measures. Among these, the Brief Index of Lupus Damage (BILD) is a patient-reported instrument for the assessment of organ damage in SLE.

Objectives: The aims of the present study are translation, cultural adaptation and validation of an Italian version of the BILD.

Methods: The process of translation and cultural adaptation followed published guidelines. $^{2}$ The final version of the questionnaire (BILDit) was pretested in a group of 30 SLE patients to evaluate acceptability, comprehension and feasibility. The validity of the BILDit was evaluated by its administering to consecutive patients attending the outpatients clinic or the inpatients wards. The external validity was tested toward the SLICC/DI scored by a physician blinded to the BILDit results. Correlation with other PROMs (FACIT, SF-36) was also tested. In a subgroup of 30 patients the questionnaire was administered twice at 2 weeks interval to assess their reliability. 